\title{
Una respuesta a los comentarios de Alexei Julio al artículo "Control de convencionalidad interamericano: una mera aplicación del derecho internacional"*
}

Agradezco a la Revista Derecho del Estado, y en particular a su editora, Paola Andrea Acosta Alvarado, la oportunidad de tener este intercambio de ideas respecto a un tema tan difundido pero pocas veces debatido. También agradezco a AleXei Julio Estrada, Secretario Jurídico de la Corte Interamericana de Derechos Humanos ${ }^{1}$, sus comentarios y calificativos al artículo "Control de convencionalidad interamericano: una mera aplicación del derecho internacional".

Para dar respuesta al comentario, lo primero que podría señalar es que es bueno saber que hay más coincidencias que diferencias, aunque por momentos pudiese parecer lo contrario. Intentaré demostrar dicho aserto a continuación.

1. Coincidimos en parte -yo afirmaría que en realidad en todo- en cuanto a la falta de precisión conceptual de la Corte Interamericana de Derechos Humanos (CorteIDH) respecto al término control de convencionalidad.

2. Aparentemente diferimos en cuanto a la exigencia del uso unívoco del término control de convencionalidad. Señalo que ello es así solo en apariencia, porque coincido con el profesor Julio en que no se le podía exigir a la CoIDH que desde su primera decisión aportara un concepto definitivo, siendo que toda creación del derecho que hacen los tribunales debe ser evolutiva, enriquecida y modificada a lo largo de los casos y de los años. Mi problema está en que eso no ha pasado con el trabajo de la CorteIDH, como lo he demostrado

* Recibido el 15 de marzo de 2015, aprobado el 21 de abril de 2015.

Para citar el artículo: K. CASTILLA. Una respuesta a los comentarios de AleXEI Julio al artículo "Control de convencionalidad interamericano: una mera aplicación del derecho internacional". Revista Derecho del Estado n. ${ }^{\circ}$ 34, Universidad Externado de Colombia, enero-junio de 2015, pp. 55-60. DOI: 10.18601/01229893.n34.03

** Abogado mexicano, doctorando y asistente de docencia de la Universitat Pompeu Fabra. Contacto: karlos.castilla@upf.edu

1 Pido se me disculpe por no conocer el nombre correcto del cargo, pero al no estar previsto en el Estatuto de la Corte Interamericana, ni en su Reglamento, no me es posible conocerlo con certeza. También desconozco el procedimiento seguido para su designación, funciones y posición en el organigrama de la Corte Interamericana, al no ser pública esa información pese a que la solicité a la OEA. Solicitud número: OAS/RFI-\#00003291. 
Aunque se dude, sí creo que los elementos fácticos han hecho cambiar a los sujetos obligados o destinatarios del falso control de convencionalidad. Incluso eso refuerza mi oposición a que se le denomine así. Lo que tal vez no he logrado explicar, es que ello en ningún caso justifica dos situaciones:

Por una parte, que se le exija lo mismo -misma operación jurídica- ex officio a un Tribunal Constitucional, a un Ministerio Público, a una autoridad administrativa o a todos los poderes y órganos estatales. Si se insiste en la relevancia del material fáctico, bien podría distinguirse en cada caso la operación jurídica que se pide a cada órgano y poner especial atención en la forma en que se ha incorporado el tratado al sistema jurídico nacional bajo análisis, si es que la Corte pretende ser congruente con lo que exige a los Estados. ¿O acaso eso no es importante precisarlo también a partir del marco fáctico en cada caso?

Entiendo que, en opinión del profesor JuLIo, no lo es, ya que él considera que el ejercicio de convencionalidad, pensando como inaplicación, busca "no aplicar el derecho interno y en su lugar aplicar una fuente a la que se reconoce una jerarquía superior". Como si ello pudiera ser determinado jurisprudencialmente por la CorteIDH, cuando no todos los Estados parte de la Convención Americana sobre Derechos Humanos (CADH) incorporan de igual forma dicho tratado y, por tanto, no todos reconocen esa supuesta superioridad jerárquica. Como si todos los órganos y poderes estatales estuvieran facultados para hacer inaplicaciones normativas.

Creo que no debemos perder de vista que la jerarquía normativa es una decisión nacional que deben tomar los órganos democráticos de cada Estado. Además de que las facultades y funciones de los poderes y órganos estatales no pueden ser determinadas por la CorteidH y su jurisprudencia. Cuestión distinta es cumplir con la obligación internacional, pero tal parece que ello se confunde, y se olvida que la CorteIDH es un tribunal internacional, es verdad, de derechos humanos, pero solo eso. Su competencia está bien definida.

Y, por otra parte, si bien podría aceptar de manera genérica el argumento respecto a los 4 casos que se citan en el comentario a manera de ejemplo, me surgen algunas preguntas: bajo ese argumento, ¿cómo se explicaría lo que ocurre, solo por citar unos ejemplos, en los casos Comunidad Indígena Xákmok Kásek ${ }^{1}$, Radilla Pacheco ${ }^{2}$ o Norín Catrimán y otros ${ }^{3}$ ? Tres de los muchos $\operatorname{casos}^{4}$ en los que la CorteIDH dirige el llamado control de conven-

1 Corte IDH.Caso Comunidad Indígena Xákmok Kásek vs. Paraguay. Fondo, Reparaciones y Costas. Sentencia de 24 de agosto de 2010 Serie C n. ${ }^{\circ} 214$.

2 Corte IDH. Caso Radilla Pacheco vs. México. Excepciones Preliminares, Fondo, Reparaciones y Costas. Sentencia de 23 de Noviembre de 2009. Serie C n. ${ }^{\circ} 209$.

3 Corte IDH. Caso Norín Catrimán y otros (Dirigentes, miembros y activista del Pueblo Indígena Mapuche) vs. Chile. Fondo, Reparaciones y Costas. Sentencia de 29 de mayo de 2014. Serie C n. ${ }^{\circ} 279$.

4 Véase Karlos Castilla Juárez, “¿Control interno o difuso de convencionalidad? Una 
cionalidad al Poder Judicial, jueces, tribunales o autoridades judiciales -sí, todas esas denominaciones ha utilizado la Corte-, cuando los elementos fácticos que dan origen al caso $\mathrm{y}$, por tanto, a la responsabilidad internacional llevarían -siguiendo la lógica de la relevancia del material fáctico- a que el falso control de convencionalidad se dirigiera no solo al Poder Judicial en cualquiera de sus acepciones antes señaladas, sino a todos o al menos a dos de los poderes y órganos estatales. ¿Por qué en esos casos no ocurre? ¿Por qué ahí -y en otros muchos casos- el marco fáctico parece no ser relevante para el resultado? ¿Eso es evolución?

O bien, ¿cómo se explicarían, a partir de los elementos fácticos, los casos Trabajadores Cesados del Congreso ${ }^{5}$ o Vélez Loor $^{6}$-este último se cita en el comentario-, que exigen no solo control de convencionalidad, sino también control de constitucionalidad a órganos del poder judicial y a órganos vinculados con la administración de justicia? ¿Eso lo puede ordenar la Corteidh? Y más aún, ¿cómo se explicaría, a partir del material fáctico, que para dirigir el falso control de convencionalidad a todas las autoridades públicas se citen en apoyo de ello precedentes en los cuales el control de convencionalidad estaba dirigido solo a jueces y órganos vinculados con la administración de justicia ${ }^{7}$, cuando ya había precedentes aplicables al supuesto específico que se desarrollaba? ¿Eso es un proceso evolutivo y congruente a partir del material fáctico y el uso del precedente? Me parece que no, por más que se me insista desde la CorteIDH.

Y finalmente en este punto, si el elemento fáctico es lo relevante, ¿cómo explicar lo que se dice en la opinión consultiva $21^{[8]}$ ? Ahí, ¿dónde está y cuál es el elemnto fáctico para decir que "los diversos órganos del Estado realicen el correspondiente control de convencionalidad”? ¿En un análisis abstracto hay elemento fáctico? Me parece que algo no va bien en su pretendida explicación o justificación del caos convencional jurisprudencial interamericano.

$\mathrm{Al}$ no encontrar respuestas que brinden certeza de ello, y sí una insistencia en responsabilizar al elemento fáctico de las vacilaciones, no puedo más que coincidir con el profesor Julio en cuanto a que hay ciertas dificultades para aproximarse a la jurisprudencia utilizando las técnicas del análisis del pre-

mejor idea: la garantía de tratados", Anuario Mexicano de Derecho Internacional, vol. xiii, 2013, pp. 58-59.

5 Corte IDH. Caso Trabajadores Cesados del Congreso (Aguado Alfaro y otros) vs. Perú. Solicitud de Interpretación de la Sentencia de Excepciones Preliminares, Fondo, Reparaciones y Costas. Sentencia de 30 de noviembre de 2007. Serie C n. ${ }^{\circ} 174$.

6 Corte IDH. Caso Vélez Loor vs. Panamá. Excepciones Preliminares, Fondo, Reparaciones y Costas. Sentencia de 23 de noviembre de 2010. Serie C n. ${ }^{\circ} 218$.

$7 \quad$ Crítica virulenta que ya se hace en la página 155 del artículo que se comenta.

8 Corte IDH. Derechos y garantías de niñas y niños en el contexto de la migración y/o necesidad de protección internacional. Opinión Consultiva OC-21/14 de 19 de agosto de 2014. Serie A n. ${ }^{\circ} 21$, párr. 31. 
cedente. Aunque me parece que diferimos en cuanto a quién tiene esas deficiencias. Pero quien lee estas líneas podrá formular sus propias conclusiones.

3. Estamos totalmente de acuerdo en el desafortunado símil que se ha hecho entre control de constitucionalidad y control de convencionalidad. Así lo he expresado y sostenido desde hace tiempo ${ }^{9}$. No cambio mi posición. Aunque vale la pena destacar que lo desafortunado del símil no surge de mi imaginación, como parece sugerirlo el profesor Julio, sino que se lo debemos a los votos que dieron origen al uso de ese término en la jurisprudencia interamericana, así como a la irreflexiva y abundante doctrina que se ha construido alrededor, mucha de la cual repite o incluso es esos mismos votos pero transformados en artículos académicos. Es bueno saber que compartimos ese punto de vista. En muchas ocasiones me sentí solo en esa crítica.

Mi insistencia en la distinción entre el control de convencionalidad y el control de constitucionalidad -sí, como justicia constitucional si se atiende a cómo surgió y se construyó la idea en la CorteidH, insisto, no resultado de mi creatividad sino objeto de mi crítica- busca, por una parte, dar su justo valor y entendimiento al verdadero control de convencionalidad o de tratados $\mathrm{y}$, por otra parte, reiterar que no es ninguna novedad más que en la creatividad y distorsión terminológica, como lo he sostenido por escrito desde el año $2010^{[10]}$.

Creo que es justo ahí donde radican nuestras diferencias, en conocer todos los precedentes y su origen, o solo parte de ellos y una historia selectiva, ya que: a) El control de convencionalidad interamericano nació como símil del control de constitucionalidad entendido como justicia constitucional. Para comprobarlo basta ver los votos donde se emplea el término y los primeros 6 casos en los que se utiliza del año 2006 al 2009. b) El control de convencionalidad crece y se amplía más allá de los poderes judiciales pero sin romper, distinguir ni apartarse de su símil de origen, simplemente se cambió y amplió el listado de sujetos obligados, pero se cortó y pegó el resto de su fraseo y formulación. c) El control de convencionalidad interamericano se desarrolla sin precisión conceptual, sin orden -ni siquiera en la cita de sus precedentes-, como una novedad, como una obligación pese a que nadie sabe caracterizar, ni puede definir con mediana precisión, como una actividad a realizar ex officio pese a no saberse qué operación u operaciones jurídicas implica.

De lo anterior me parece evidente que después del año 2009 el control de convencionalidad interamericano no es lo que parecía ser en su origen,

9 Véase CAstilla JuÁrez, “¿Control interno o difuso de convencionalidad? Una mejor idea: la garantía de tratados", cit., pp. 55, 71 y 72 , al menos.

10 Véase Karlos Castilla Juárez, "El control de convencionalidad: un nuevo debate en México a partir de la sentencia del caso Radilla Pacheco", Anuario Mexicano de Derecho Internacional, vol. xI, 2011, p. 596. 
que no se sabe bien qué es ni siquiera al interior de la CorteidH. Se olvida y altera su origen. Se justifica selectivamente olvidando todos los precedentes, si de evolución se pretende hablar. Al analizar todo e intentar dar congruencia es porque afirmo en mi tercer artículo del tema que es una mera aplicación del derecho internacional. Que es cumplir con las obligaciones adquiridas internacionalmente. Nada nuevo desde su origen, pese a que en su origen parecía al menos un ejercicio interesante -siempre debatible- y con un objetivo claro cuando solo se puso énfasis en el Poder Judicial con las diferentes acepciones que ha utilizado la CorteIDH.

No me cansaré de decirlo: todas las autoridades y órganos de todos los Estados parte de la CADH deben cumplir con las obligaciones que derivan de esta, con su objeto y su fin. Pero ello no es nada nuevo, ni es control de convencionalidad. Ello es un elemento esencial del derecho internacional y según cada país, es control de constitucionalidad o de legalidad, dependiendo del lugar que se le asigne en cada sistema jurídico nacional. Tal vez es necesario no olvidar que los tratados son derecho interno de origen internacional. Normas que toda autoridad debe observar y cumplir, no porque lo diga la CorteIDH, sino porque el Estado se obligó internacionalmente y decidió que ello se incorporara a su sistema jurídico nacional.

Por eso insistiré en lo poco afortunado de llamar a esa aplicación interna de tratados o cumplimiento de obligaciones internacionales como control de convencionalidad. Por eso he propuesto la idea de la garantía de tratados, si un nombre se le quiere dar a la obligación de cumplir con el objeto y fin de los tratados, de las obligaciones internacionales transformadas en derecho nacional. Sé que parece irreversible el uso del término control de convencionalidad, y lo lamento por lo imperfecto que es al carecer de base conceptual, no solo por lo que parece. Pero sin duda alguna, es muy bueno estar debatiendo, contrastando y reflexionando, pues solo así se pueden construir mejores sistemas de protección.

Con esto creo haber dado respuesta al comentario y quedo abierto al intercambio de más ideas. Ojalá desde el interior de la CorteIDH se hicieran más ejercicios como este. Artículos, foros y congresos centrados en la adulación de resultados fortalecen amistades, pero no necesariamente a los sistemas de protección y garantía de los derechos humanos.

Finalmente, como una muestra de que las cosas aún pueden cambiar y corregirse, no puedo dejar de señalar que en el marco del Congreso "Diálogos Judiciales en el Sistema Interamericano de Garantía [sic] de los Derechos Humanos", celebrado en la Universitat Pompeu Fabra en febrero de 2015, tanto el juez Roberto Caldas, Vicepresidente de la Corteidh, como el Presidente de la misma, Humberto Sierra, coincidieron en que el fundamento del llamado control de convencionalidad está en los artículos 1, 2, 28, 29 y 68 de la CADH. Lo que significa que por primera vez, al menos que yo tenga 
conocimiento, desde la CorteidH sus integrantes ofrecen un fundamento jurídico concreto del llamado control de convencionalidad.

Ese fundamento ya lo había propuesto quien escribe estas líneas desde el año 2013 para respaldar la idea de la garantía de tratados. Con lo que se confirma que, como siempre lo he señalado, no es ninguna novedad y que, según lo decía en el artículo que se comenta, el tiempo va poniendo las cosas en el lugar que les corresponde.

El Presidente de la CorteidH en ese mismo evento académico expuso unas líneas que en mucho se ajustan a lo que desde hace largo tiempo he sostenido. No las adelanto al no constar aún por escrito. Lo que sí es que esperemos que las expresiones anteriores y la nueva integración que tendrá la CorteidH a partir del 1 de enero de 2016 nos lleven a poner al fin las cosas en su lugar, a reconocer errores y dar a todo su justa medida.

Los sistemas de derechos humanos requieren de certeza antes que de creatividad irrealizable. 